\title{
EDITH DE MAGALHÃES FRAENKEL ${ }^{1}$
}

Faleceu em 5 de abril de 1968, no Rio de Janeiro, aos 79 anos de idade, a Sra. Edith de Magalhães Fraenkel, primeira presidente eleita da Associação Brasileira de Enfermagem e uma de suas fundadoras.

Filha de Karl Fraenkel e Aldina Botelho de Magalhães Fraenkel, neta de Benjamin Constant, herdou de seus antepassados, a energia, o caráter, o idealismo e a firmeza de conviç̧ões.

Nascida a 9 de maio de 1889, no Rio de Janeiro, ali viveu até 1892, quando seu pai foi nomeado consul do Brasil em Berlim e a familia se transladou para a Alemanha. Em 1901 foi transferido para Estocolmo Suécia, e em 1903 para Montevidéu, Uruguai, sendo sempre acompanhado pela familia.

Após a morte de Karl Fraenkel, em 1906, a família fixou-se definitivamente no Rio de Janeiro. A jovem Edith, então com 15 anos, que fizera todo o curso primário e iniciara os estudos secundários no exterior, termina êstes últimos na escola Alemã, hoje Cruzeiro. Faz, posteriormente o curso de "Enfermeira de Guerra da Cruz Vermelha" e o curso para Visitadoras do Serviço de Tuberculose, tendo permanecido neste como chefe do Serviço de Visitadoras.

Em 1922 obtém bolsa de estudos da Fundação Rockefeller para estudar enfermagem nos Estados Unidos, e em abril do mesmo ano, ingressa na Escola de Enfermagem do Hospital Geral de Filadélfia, onde, em 1925, recebe o diploma de enfermeira.

Regressando ao Brasil é imediatamente nomeada instrutora da Escola de Enfermeiras do Departamento Nacional de Saúde Pública, que depois veio chamar-se Escola Ana Néri.

Em 1927 é nomeada enfermeira chefe da Divisão de Enfermagem daquele Departamento e, em 1928, superintendente da mesma Divisão. Sob seu comando desenvolveu-se brilhantemente a enfermagem de saúde pública do Rio de Janeiro e o mesmo serviço foi iniciado em muitos estados.

No decênio 1930-1940 inúmeras e variadas são as atividades de Edith de Magalhães Fraenkel. Funda no Rio de Janeiro, o serviço de Obras Sociais, SOS, para dar assistência social à população atendida pelo serviço de enfermagem de saúde pública; coopera na fundação da primeira Escola de Serviço Social do pais; ao lado de Bertha Lutz luta pelo direito da mulher ao voto, com sucesso.

Em 1940, ao ser extinta a Divisão de Enfermagem do Departamento Nacional de Saúde Pública, é convidada pelo Governo do Estado de São Paulo para organizar a Escola de Enfermagem da Universidade de São Paulo. Afim de se preparar para as novas funções, visita escolas de enfermagem dos Estados Unidos e Canadá, com bolsa de estudos da Fundação Rockefeller. De volta ao Brasil, em 1941 , inicia as atividades de preparo não só da futura escola, como do serviço de enfermagem do futuro Hospital das Clínicas.
Criada a Escola de Enfermagem, em 1942, Edith de Magalhães Fraenkel é nomeada Diretora, cargo que ocupou até sua aposentadoria em 1955. Ai sua atuação deixou marcas indeléveis. Graças a sua visão de administradora e educadora, essa Escola passou a ter grande projeção no cenário da enfermagem brasileira.

A aposentadoria, contudo, não põe ponto final às suas atividades de enfermagem. De 1956 a 1961 é coordenadora do Departamento de Ensino da Escola de Enfermagem Alfredo Pinto.

À Associação Brasileira de Enfermagem deu Edith de Magalhães Fraenkel talvez o melhor de sua capacidade. Foi sua presidente de 1928 a 1938; quando esta praticamente deixou de existir, no início da década de quarenta, foi ela quem a fez reviver, em 1944; foi novamente presidente de 1944 a 1946 e de 1948 a 1950. Representou-a em três congressos do Conselho Internacional de Enfermeiras, ICN: em Montreal, Canadá, em 1929, quando a ABEn filiou-se ao ICN; em Atlantic City, Estados Unidos, em 1947 e em Estocolmo, Suécia, em 1949. Nesta oportunidade convidou - ICN para realizar o seu próximo congresso no Brasil, o que se deu em julho de 1953, em Petrópilis, RJ.

Foi a fundadora e primeira presidente (1946-1948) da Associação Brasileira de Enfermagem, Seção São Paulo.

Quando em Montreal, para o congresso do ICN, em 1929, foi convidada a participar de uma reunião de redatoras de revistas de enfermagem. Entusiasmada com a idéia voltou ao Brasil disposta a lançar uma revista, o que conseguiu com a cooperação de Rachel Haddock Lobo e Zaira Cintra Vidal. O primeiro número de Anais de Enfermagem - hoje Revista Brasileira de Enfermagem - foi publicado em 1932. Interrompido em 1941 foi ainda Edith de Magalhães Fraenkel quem começou a sua publicação em 1946. Até sua morte interessou-se profundamente pelo destino da Associação que havia ajudado a criar. Escreveu o seu histórico que se acha em vias de publicação. Por esse motivo e por sua atuação extensa e definitiva na enfermagem brasileira, recebeu significativa homenagem das Seções da ABEn, São Paulo e Guanabara. Em 1968 foi contemplada com Menção Honrosa do Prêmio "Enfermeira do Ano".

Durante os seus últimos anos de vida freqüentou diariamente a sede da ABEn, no Rio de Janeiro. Enquanto teve forças, colaborou como voluntária, nos trabalhos de secretária e emprestou sua rica experiência na solução dos problemas ali surgidos. A idade, a doença e os muitos problemas particulares que enfrentou, não conseguiram abalar sua dedicação pela Associação Brasileira de Enfermagem.

Morreu num Sábado de Aleluia.

Que Deus dê a sua alma o merecido descanso.

${ }^{1}$ Texto publicado na Revista Brasileira de Enfermagem por ocasião do falecimento de Edith de Magalhães Fraenkel. (Rev. Bras. Enferm., Rio de Janeiro, ano xxii, n. 1/2/3, p.7-9, jan./ jun. 1969). 